\title{
FACTORES LIMITANTES A LA PRODUCCIÓN Y USO DE LA PAPA: RESULTADOS DE LA ENCUESTA A LOS PROGRAMAS NACIONALES DE AMERICA LATINA
}

\author{
José E. Herrera*; Gregory J. Scott**
}

\section{RESUMEN}

Para ayudar a mejorar la relación entre las necesidades de los países en desarrollo y los objetivos de la investigación agrícola intemacional, el Centro Internacional de la Papa (CIP) envió un cuestionario a los líderes de los Programas Nacionales de este cultivo en América Latina, y les pidió su opinión sobre la importancia de 71 factores limitantes a la producción y uso de dicho cultivo. Después de una breve descripción de la metodología empleada, este trabajo presenta los principales resultados de la encuesta. Entre los resultados más sobresalientes está la percepción común de los efectos negativos de precios y producción inestables y la poca importancia que se asigna en el conjunto de países a los nematodos. La información presentada sugiere vínculos más estrechos entre países que enfrentan problemas similares, con el fin de colaborar a diseñar estrategias que optimicen el impacto de la investigación sobre el cultivo y uso de la papa.

Palabras claves adicionales: análisis discriminante, investigación colaborativa, problemas de poscosecha.

Aceptado para publicación: febrero 6, 1995

* Estudiante del Programa de Postgrado en Economía - Universidad del Estado de Carolina del Norte. P.O. Box 8109. Students Office. Raleigh, NC 27695-8109, USA.

* * Economista, Investigador Principal y Lider del Programa de Poscosecha. Centro Internacional de la Papa. Apartado 1558, Lima 100, Perú 


\section{SUMMARY}

\section{LIMITING FACTORS FOR THE PRODUCTION AND USE OF POTATO: RESULTS OF A SURVEY TO THE NATIONAL PROGRAMS OF LATÍN AMERICA}

As part of a continuous effort to link the needs of developing countries and the focus of International agricultural research, CIP scientists surveyed National Potato Program leaders in Latin America to record their opinions about the importance of 71 constraints to the production and utilization of potatoes so as to improve the existing data base on potato problems. After a brief description of the survey techniques utilized, this article presents the main results of that survey. A distinction is made between countries with high and low production. The findings indicate, among other things, the perceived high negative effects of price and production instability and the minor importance of nematodes for potato production and utilization. This information should prove useful in guiding collaborative efforts between countries to optimize the impact of future research on production and utilization of potatoes.

Additional index words: Discriminant analysis, collaborative research, postharvest problems.

La investigación sobre papa generalmente se ha desarrollado a nivel de cada país, como respuesta a las preocupaciones locales sobre el cultivo (véase por ejemplo 1,3). Por su parte, la investigación regional se ha centrado en una sola disciplina o área de estudio (6). La escasez de recursos en cada país y los posibles beneficios del intercambio de métodos y resultados, resaltan la utilidad de identificar los principales factores limitantes comunes a grupos de países.

El objetivo del presente estudio es identificar los principales factores que limitan la producción y utilización de la papa en América Latina. La metodología consiste en la recopilación de información de líderes de Programas Nacionales y de expertos, sobre localidades específicas de su país. El sondeo se realizó en los países en desarrollo más representativos en cuanto a producción de papa, y los principales resultados para este conjunto de países ya han sido presentados parcialmente en otros documentos (2, 9). En el presente artículo se analiza en detalle el caso de America Latina, con el fin de determinar si los factores limitantes presentan 
uniformidad entre zonas de producción con características comunes entre países de una misma región.

Los resultados permiten evaluar algunas de las principales necesidades de los Sistemas Nacionales de Investigación Agropecuaria (SNIA), agricultores, agentes de comercialización y consumidores, generando información útil para el establecimiento de prioridades de investigación colaborativa regional sobre el cultivo de papa. Dentro de América Latina se han hecho subdivisiones por grupos de países, de acuerdo a los volúmenes de producción y a la subregión geográfica.

\section{MATERIALES Y MÉTODOS}

La información sobre factores limitantes se recopiló mediante un cuestionario en el que se solicitaba una apreciación de la importancia de 71 factores considerados como problemáticos en la producción de papa. Estos factores se clasifican en 12 grupos que abarcan distintas etapas de la producción y poscosecha de papa (ver Tabla 1). La importancia de cada factor limitante se evalúa según la siguiente escala:

$0=$ Factor ausente;

$1=$ Factor de poca importancia;

$2=$ Factor de importancia; $y$,

$3=$ Factor de mucha importancia.

Se recibió información de 14 países de América Latina y de 43 localidades identificadas según su ubicación, altitud, régimen predominante de riego, principal destino de la producción, etc. Los países comprendidos concentraron el 58\% de la superficie anual promedio cosechada de papa en el período 198688, y el 62\% del volumen anual promedio de la región para el mismo período según los datos de FAO.

Con el procesamiento de la información se buscó identificar los factores limitantes estadísticamente representativos para el conjunto de países correspondientes. Pero además, para llegar a conclusiones menos generales, las observaciones fueron agrupadas según características similares bajo la hipótesis de que tal similitud podría reflejar factores limitantes uniformes.

La primera clasificación considera América Latina en su conjunto. Además, al interior de América Latina se forman agrupaciones según volumen de producción y subregiones geográficas.

El propósito de evaluar agrupaciones según distintos criterios, es conocer los aspectos problemáticos predominantes en la región, al margen de apreciaciones que puedan ser introducidas al considerar una sola clasificación. 
El procedimiento busca las $\mathrm{k}(\mathrm{k}=8)$ observaciones que tienen más afinidad ("vecinos más cercanos") y determina si cada observación presenta las características del grupo en el que ha sido clasificada o si debe ser cambiada a un nuevo grupo. Una vez evaluadas las agrupaciones, el siguiente paso es identificar los principales factores limitantes de cada grupo. Para ello se utilizan medidas de tendencia central que permiten determinar los factores que tienen mayor importancia.

Tabla 1. Factores limitantes a la producción y uso de papa en América Latina: Limitantes individuales, promedios $(X)$ ponderados (con desviación estándar) por producción

\begin{tabular}{ccc}
\hline & & \\
\cline { 2 - 3 } & $\mathrm{x}$ & $\mathrm{s}$ \\
\hline
\end{tabular}

PROBLEMAS DE PRODUCCION

\section{Variedades inadecuadas}

1. Madurez muy tardía

$0.9 \quad 1.3$

2. Madurez muy temprana

$0.6 \quad 1.2$

3. Periodo de reposo corto

$0.7 \quad 1.4$

4. Período de reposo largo

$1.1 \quad 1.6$

5. Poca aceptación en el mercado

$0.8 \quad 1.0$

6. Inadecuada para procesamiento

$1.1 \quad 1.4$

7. Inadecuada para alimentación de ganado

$0.3 \quad 0.5$

Problemas con el tubérculo semilla

8. Problemas sanitarios

$2.0 \quad 2.0$

9. Problemas fisiológicos

$1.0 \quad 1.5$

10. Escasez

11. Alto costo

$1.4 \quad 1.6$

Enfermedades bacterianas

12. Marchitez bacteriana

13. Pierna negra

14. Pudrición blanda de tubérculos

Enfermedades fungosas

$\begin{array}{lll}\text { 15. Tizón tardío } & 1.5 & 1.8 \\ \text { 16. Tizón temprano } & 1.3 & 1.5 \\ \text { 17. Pudrición seca del tubérculo } & 0.9 & 1.2 \\ \text { 18. Rizoctoniosis } & 1.4 & 1.5 \\ \text { 19. Verruga } & 0.4 & 0.8\end{array}$

\section{Enfermedades viróticas}

20. Virus de enrollamiento de las hojas $\quad 2.1 \quad 2.1$

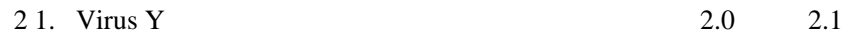

22. Micoplasmas $\quad 0.40 .6$

\section{Nematodos}

23. Nematodos del quiste

24. Nematodos del nódulo de la raíz

\section{Insectos y ácaros}

25. Polilla de la papa

26. Gorgojo de los Andes

27. Mosca minadora

28. Cigarritas verdes

29. Áfidos

$1.5 \quad 1.8$




\begin{tabular}{llcc} 
& $\mathrm{X}$ & $\mathrm{S}$ \\
\hline 30. Trips & 0.7 & 1.2 \\
31. Cochinilla harinosa & 0.2 & 0.5 \\
32. Gusanos cortadores & 0.8 & 1.0 \\
33. Ácaros & 0.4 & 0.7
\end{tabular}

Problemas del ambiente

34. Frío, heladas o granizo

35. Calor

36. Sequía

37. Suelos muy húmedos

38. Energía solar baja (nubosidad)

39. Maleza

$0.8-1.1$

40. Baja fertilidad del suelo

$1.3 \quad 1.4$

41. Salinidad del suelo

42. Bajo pH del suelo

$0.1 \quad 0.3$

43. Toxicidad causada por el aluminio

44. Estructura pobre del suelo

PROBLEMAS DE POSCOSECHA

Almacenamiento del tubérculo semilla

Problemas de almacenamiento

45. Enfermedades (pudrición)

46. Insectos

47. Roedores

48. Brotación

49. Desecación

50. Diseño inadecuado de los almacenes

51. Capacidad insuficiente de almacenamiento

52. Altos costos de almacenamiento

Almacenamiento de papa para consumo

Problemas de almacenamiento

53. Enfermedades (pudrición)

54. Insectos

55. Roedores

56. Brotación

57. Desecación

58. Diseño inadecuado de los almacenes

59. Capacidad insuficiente de almacenamiento

60. Altos costos de almacenamiento

\section{Problemas de comercialización}

61. Problemas de transporte

62. Inestabilidad de los precios y producción

63. Altos costos de comercialización

64. Pérdidas físicas durante la comercialización

\section{Demanda}

65. A la gente no le gusta comer papas

66. Falta variedad con cualidades para comer

67. La papa no está en la dieta tradicional

68. Poca disponibilidad

69. Precio alto

70. Falta de productos procesados

71. Falta variedad con cualidades para procesar 


\section{RESULTADOS}

Análisis discriminante: Mediante el análisis discriminante se encontró que los países de América Latina presentan patrones de comportamiento similares. Al establecerse divisiones al interior de América Latina, se consideró el criterio de importancia de la producción, agrupando a los países por el volumen promedio anual producido en el período 1986-88, según haya sido mayor o menor que la mediana de la muestra total (70,000 toneladas).

De 26 observaciones clasificadas en el grupo de grandes productores (producción anual mayor a 70,000 t), 25 estuvieron correctamente agrupadas, y de 17 observaciones correspondientes a países de menor producción, 16 lo fueron. Es decir, el $95.1 \%$ de las observaciones tenía las características del grupo al que fueron asignadas.

Principales factores limitantes: El análisis discriminante permitió identificar los principales factores uniformes que limitan la producción y utilización de papa en América Latina. Un primer factor es la importancia que se le asigna a los problemas de comercialización y poscosccha, como precios, costos, almacenamiento y demanda. En grupo, los problemas de comercialización y poscosecha reciben los dos más altos porcentajes de los 71 factores limitantes y 4 de los 10 más altos (Tabla 1).

La inestabilidad de los precios y la producción es considerada la restricción más importante para una mayor producción de papa, tanto en el caso de países de baja como los de alta producción de ese cultivo. Este factor actúa elevando el riesgo de los productores. El productor al no tener la certeza de un resultado favorable, se orientaría hacia otros productos, dado el costo relativamente elevado de la producción de papa.

Otros factores de importancia están referidos a las enfermedades viróticas y fungosas. La incidencia del virus del enrollamiento de la hoja (PLRV) y del tizón tardío destacan entre los principales factores limitantes, que incrementan el riesgo de pérdidas, elevan los costos necesarios para combatir las enfermedades, y disminuyen los rendimientos, reduciendo así la rentabilidad del productor. Se ha señalado además que hay problemas con la calidad sanitaria del tubérculo-semilla disponible, de manera que se reduce el atractivo de producir papa al presentarse mayores costos, mayor riesgo de pérdida y menores rendimientos.

Además de los mencionados, el problema de mercadeo recibe atención en la medida en que la comercialización permite al productor percibir el resultado económico de la campaña. Así, los elevados costos de comercialización que pueden traducirse en precios altos, estarían desincentivando la demanda en algunos casos, y en otros disminuyendo la participación del productor en el precio final. 


\section{Análisis por grupos de países:}

Según volumen de producción: Puede plantearse que los problemas que afectan a los países de mayor producción no son los mismos que los de producción menor. Como se señaló anteriormente, el análisis discriminante, aplicado para clasificar a los países según una producción anual promedio de 70,000 t de papa en el período 1986-88, indicó que la información disponible permitía distinguir ambos grupos de países. La evaluación de los factores limitantes que afectan a cada grupo indica que la inestabilidad de precios y de oferta, continúan siendo el principal problema para expandir la producción de papa (Tabla 2).

En los países de menor producción (los centroamericanos principalmente), la demanda de papa está restringida por el elevado precio que tiene en el mercado, mientras que en los de mayor producción los altos márgenes de comercialización aparentemente se traducen en menor ingreso para el productor, desincentivándolo.

Los problemas de material de siembra están considerados entre los principales factores limitantes en ambos grupos; específicamente el problema radica en una baja calidad sanitaria del tubérculo-semilla. En los países de menor producción se presenta además un problema de escasez.

El tizón tardío es considerado un factor de mayor importancia en los países de menor producción, mientras que en los de mayor producción se percibe como un problema de mediana importancia. En estos últimos, se otorga prioridad a la presencia del virus de enrollamiento de la hoja.

Según subregión geográfica: Una subdivisión que ofrece ideas adicionales sobre el cultivo de papa en América Latina, es la que agrupa a los países del Cono Sur (Argentina y Uruguay), los del Área Andina (Colombia, Ecuador, Perú y Venezuela), y los de Centroamérica y el Caribe. La muestra de la encuesta contiene 8 observaciones del primer grupo, 15 del segundo y 20 del tercero (Tabla3).

Tanto para los países del Área Andina, como para Centroamérica y el Caribe, el principal problema mencionado se refiere a la inestabilidad de precios y producción. En el Área Andina, adicionalmente, los altos costos de comercialización inciden en una menor producción de papa.

En el Cono Sur de América Latina, en cambio, la principal dificultad mencionada fue la calidad sanitaria del tubérculo-semilla. En esta subregión también se otorgó importancia al ataque de enfermedades fungosas (Rizoctoniasis) e insectos (áfidos), así como a los altos costos de comercialización. 
Tabla 2. Principales factores limitantes a la producción y uso de papa en América Latina según volumen de producción.

PAÍSES PRODUCTORES PEQUEÑOS (<70,000t/año)

\begin{tabular}{|c|c|c|c|}
\hline Localidades & & & \\
\hline & 1 & 2 & 3 \\
\hline Inestabilidad de precios y producción & XII & 2.8 & 0.4 \\
\hline Precio alto & IX & 2.5 & 0.9 \\
\hline Tizón tardío de la papa & IV & 2.4 & 0.8 \\
\hline Polilla de la papa & VII & 2.3 & 1.0 \\
\hline Virus de enrollamiento de la hoja (PLRV) & $\mathrm{V}$ & 2.1 & 0.9 \\
\hline Problemas sanitarios & II & 2.1 & 1.1 \\
\hline Escasez & II & 2.1 & 1.2 \\
\hline Áfidos & VII & 2.0 & 0.8 \\
\hline Insectos & $\mathrm{X}$ & 1.9 & 1.0 \\
\hline Falta de productos procesados & IX & 1.9 & 1.0 \\
\hline Diseño inadecuado de almacenes & $\mathrm{X}$ & 1.8 & 0.8 \\
\hline Altos costos de comercialización & XII & 1.6 & 1.2 \\
\hline Falta variedad con cualidades para procesar & IX & 1.6 & 1.2 \\
\hline Capacidad insuficiente de almacenamiento & $\mathrm{X}$ & 1.6 & 0.8 \\
\hline La papa no está en la dieta tradicional & IX & 1.5 & 1.3 \\
\hline Problemas de transporte & XII & 1.4 & 0.8 \\
\hline Pierna negra & III & 1.4 & 1.0 \\
\hline Inadecuadas para procesamiento & I & 1.4 & 1.2 \\
\hline Enfermedades (pudrición) & $\mathrm{X}$ & 1.4 & 0.8 \\
\hline Alto costo & II & 1.4 & 1.5 \\
\hline \multicolumn{4}{|c|}{ PAÍSES PRODUCTORES GRANDES (>70,000t/año) } \\
\hline
\end{tabular}

\begin{tabular}{|c|c|c|c|}
\hline $\begin{array}{ll}\text { Localidades } \quad 26\end{array}$ & & & \\
\hline & 1 & 2 & 3 \\
\hline Inestabilidad de precios y producción & XII & 2.3 & 1.0 \\
\hline Virus de enrollamiento de la hoja (PLRV) & $\mathrm{V}$ & 2.1 & 0.8 \\
\hline Altos costos de comercialización & XII & 2.0 & 0.8 \\
\hline Problemas sanitarios & II & 1.9 & 0.7 \\
\hline Tizón tardío de la papa & IV & 1.9 & 1.0 \\
\hline Virus Y de la papa (PVY) & $\mathrm{V}$ & 1.8 & 0.7 \\
\hline Áfidos & VII & 1.8 & 0.9 \\
\hline Diseño inadecuado de almacenes & $\mathrm{X}$ & 1.7 & 0.9 \\
\hline Pérdidas físicas & XII & 1.7 & 0.7 \\
\hline Problemas fisiológicos & II & 1.6 & 1.0 \\
\hline Pierna negra & III & 1.5 & 0.7 \\
\hline Escasez & II & 1.5 & 1.1 \\
\hline Tizón temprano & IV & 1.5 & 0.7 \\
\hline Pudrición blanda de tubérculos & III & 1.5 & 0.7 \\
\hline Sequía & VIII & 1.4 & 0.8 \\
\hline Rizoctoniosis & IV & 1.4 & 0.6 \\
\hline Alto costo & II & 1.4 & 1.0 \\
\hline Capacidad insuficiente de almacenamiento & $\mathrm{X}$ & 1.4 & 1.1 \\
\hline Enfermedades (pudrición) & $\mathrm{X}$ & 1.3 & 0.7 \\
\hline Frio, heladas y granizo & VIII & 1.3 & 1.1 \\
\hline
\end{tabular}

\section{Grupos de factores limitantes}

I Variedades inadecuadas

II Problemas con el tubérculo semilla

I I I Enfermedades bacterianas

IV Enfermedades fungosas

$\mathrm{V}$ Enfermedades viróticas

VI Nematodos
V II Insectos y Ácaros

VIII Problemas del ambiente

$\mathrm{X}$ Almacenamiento de tubérculo semilla

XI Almacenamiento de papa para consumo

XII Problemas de comercialización

2 Promedios

3 Desviaciones Estándar 


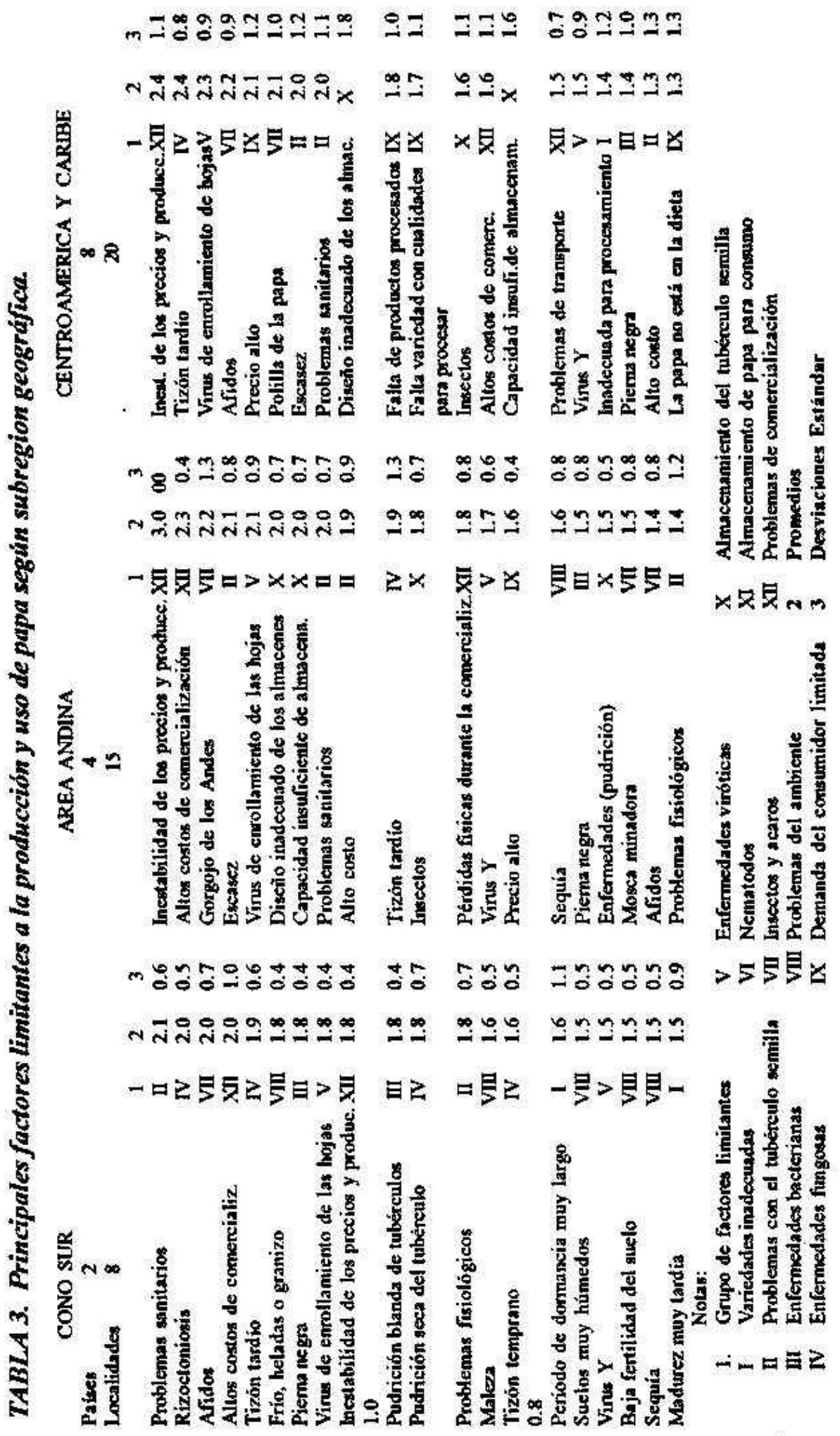


La semilla es un problema común para la región, aunque los problemas específicos varían en importancia según la zona; en el Área Andina y en Centroamérica y el Caribe, los problemas de semilla se refieren principalmente a su escasez y almacenamiento (capacidad y diseño de almacenes). En el Cono Sur, el problema de semilla se manifiesta en los aspectos sanitarios y fisiológicos.

\section{DISCUSIÓN}

Los resultados presentados en este trabajo ilustran la forma en que se pueden identificar y correlacionar los distintos problemas que afectan la producción de papa. Hasta la fecha, no se había intentado medir de forma sistemática, y abarcando distintas disciplinas, la importancia de los diferentes factores limitantes para ver aspectos comunes.

Resulta interesante mencionar que el procedimiento de realizar distintos cortes transversales de la información, mediante la utilización de diferentes criterios de agrupación, lleva a apreciar aquellos factores limitantes que tienen mayor relevancia. En el caso de la información analizada, independientemente del criterio de agrupación que se adopte, los principales factores limitantes se refieren a los problemas de poscosecha (inestabilidad de precios y de producción, costos de comercialización), y de semilla (escasez, problemas sanitarios y alto costo del tubérculo-semilla).

Lo anterior permite apreciar aspectos interesantes sobre los que los Programas Nacionales tienen la posibilidad de actuar. Por un lado, el énfasis puesto en los problemas del mercado, especialmente en cuanto a incertidumbre de precios y producción plantea un reto en términos de cómo actuar para reducir la incertidumbre acerca del futuro de estas variables.

Por su parte, los problemas comunes de semilla en la región latinoamericana, constituyen un punto de partida para fortalecer vínculos colaborativos entre los programas de semilla de los países, y también para plantear una mejor adecuación de los programas a las necesidades de la producción, incidiendo en los factores que resultan más problemáticos.

Limitaciones del análisis y de la metodología: Los resultados podrían ser mejorados ampliando la muestra, especialmente en aquéllos grupos en los que no se tienen apreciaciones del todo significativas, ya que para algunos grupos la muestra ha resultado pequeña. Hay que reconocer a )a vez, que los resultados pueden ser mejor apreciados como tendencias relativas que como diferencias absolutas, debido a que las desviaciones estándares son relativamente altas, más aún en los casos en los que el puntaje sugiere una muy grande o poca importancia. 
Un segundo problema proviene de la selección de las personas encuestadas, dado que han sido de diversas especialidades. Esto podría estar introduciendo un sesgo, ya que se puede responder con mayor exactitud sobre los temas que se conocen, siendo mas intuitivos los puntajes de los temas menos conocidos.

Otro problema de sesgo puede estar ocurriendo en los casos en que la persona encuestada tenga mayor conocimiento de una localidad de su país frente a otras. En este caso, puede haber una tendencia a generalizar los problemas de la localidad conocida, al resto de localidades. Los problemas metodológicos presentados son propios de los estudios que utilizan encuestas. En todo caso la forma de realizar el muestreo, y posteriores ajustes pueden mejorar la calidad de la información.

\section{CONCLUSIONES Y RECOMENDACIONES}

De la información obtenida se establecen algunas prioridades posibles en cuanto a las áreas de investigación que requieren ser reforzadas.

Ante la inestabilidad de precios y de producción, resulta útil el desarrollo de sistemas de información que permitan tanto a los participantes en la comercialización, como a los formuladores de política, tener los indicadores básicos para orientar sus decisiones. Los avances en el desarrollo de sistemas de información de bajo costo por el Programa Nacional del Perú, merecen ser mencionados como una respuesta a este problema (4). También hay que señalar la alternativa que representa el uso creciente de papa en procesamiento en Colombia, como medio de atenuar los efectos de las fluctuaciones marcadas en la producción y los precios (7).

La necesidad de superar deficiencias en la disponibilidad de semilla, se presenta como un campo de acción para los distintos programas de semilla de los países latinoamericanos, que podrían profundizar el intercambio de experiencias positivas que otros países ya hayan puesto en práctica (5).

Una tercera área en que se perciben necesidades es la profundización de los trabajos con variedades, para generar las más adecuadas según el uso y los hábitos de cada medio.

Finalmente, se llama la atención sobre algunos problemas de poscosecha como almacenamiento y sistemas de comercialización, que actúan sobre los costos y elevan el precio final del producto. Los esfuerzos para desarrollar metodologías para analizar la comercialización agrícola, pueden servir para superar este problema, como lo sugiere Scott (8). 
La riqueza de la información obtenida puede apreciarse en la medida que los resultados sean interpretados de una manera integral, considerando no solamente el orden de magnitud de los factores limitantes individuales, sino también la importancia comparativa que tienen entre distintos grupos, y también la forma como se relacionan dentro de un mismo grupo.

Un siguiente paso sería establecer, al interior de cada grupo, correlaciones entre factores limitantes referidos a distintas disciplinas o áreas de estudio, para identificar relaciones de causa-efecto que den una mejor orientación sobre los problemas que requieren mayor atención.

Debe tenerse en cuenta la importancia de la forma de agrupar las observaciones, ya que de ello depende que se identifiquen adecuadamente los factores limitantes más representativos. Una agrupación incorrecta distorsionará la importancia relativa de cada problema.

\section{REFERENCIAS BIBLIOGRÁFICAS}

1. Amador, P.R. 1988. Situación del cultivo de la papa en Costa Rica. En: ICTA; PRECODEPA; CIP. Seminario Internacional de Transferencia de Tecnología en el Cultivo de la Papa. ICTA, Guatemala, p. 2-7.

2. Centro Internacional de la Papa (CIP), 1990. Informe Anual del CIP, 1989. CIP, Lima, Perú. 178p.

3. Corzo, P. 1990. Situación Actual y Factores Limitantes en la Producción y Distribución de Tubérculos Semillas de Papa en Colombia. En: CIP. 1990. Seminario Taller: Metodologías para la Investigación Agronómica y Socioeconómica de la Producción y Distribución de Tubérculos-Semillas de Papa. Quito, Ecuador.

4. Chumbe, V; Cavero W. 1990. Un sistema de información para mejorar las decisiones de producción y comercialización de papa. Ponencia presentada, en el Taller Latinoamericano sobre Métodos para Estudiar la Comercialización Agrícola, realizado en el Centro Internacional de la Papa (CIP), Lima, Perú, del 11 al 13 de junio de 1990.

5. Herrera, J.; Scott, G.J. 1991. Sistemas de comercialización rural en América Latina: El caso de la semilla de papa en los países del área andina. Ponencia presentada en la XV reunión de la Asociación Latinoamericana de la Papa (ALAP), realizada en Lima del 8 al 14 de setiembre de 1991. 
6. Hidalgo, O. 1989. Virus and viroid detection techniques: Status, constraints and needs in NARS of Latin America. EN: CIP, 1990. Control of viruses and virus-like diseases and sweet potato. p. 5158

7. Rodríguez, P.; Rodríguez, A. 1992. Caracterización del uso y determinación de necesidades de los procesadores de papa en Colombia. En: Scott, G., Herrera J.E, Espinola N., Daza M., Fonseca C., Fano, H., Benavides M. (eds). Desarrollo de productos de Raíces y Tubérculos. Volumen II, CIP, Lima Perú. 375 p. +xxii.

8. Scott, G. 1991. La Investigación de Mercadeo Agrícola y los Institutos Nacionales de Investigación Agrícola. EN: G.J.Scott y J.E. Herrera (eds). Mercadeo Agrícola: Metodologías de Investigación. Selección de las ponencias presentadas en el “Taller Latinoamericano sobre Métodos para Estudiar la Comercialización Agrícola” realizado en el Centro Internacional de la Papa (CIP), Lima, Perú, del 11 al 13 de junio de 1990; en colaboración con el Instituto Interamericano de Cooperación para la Agricultura (IICA), San José, Costa Rica. 503 p.

9. Scott, G. 1990b. CIP's Mission and Molecular Techniques for Germplasm Enhancement: Some Strategic Considerations for Future Impact. En: CIP, 1991. Molecular Methods for Potato Improvement. Report of the Planning Conference on "Application of Molecular Techniques to Potato Germplasm Enhancement”, Lima, Perú, Marzo de 1990. p. 12-22. 